\title{
トラベラ一の滑走姿勢とその影響に 對する調整*
}

昭和24年7月11日受理會員田 中 英 世 世* $^{*}$

\section{1 緒論}

俥てスフの混紡䒺が精紡機で紡績されてんる狀態 が非常に良くなんので私等の立場からトラベラー とリングとの䦛係在目して調查したよてろトラ ベラーの姿勢が良くなんてとに氣付んた。リング にはLG型トラベラーが脚けられているのに対し フランヂの巾が狹すぎて姿勢が崩れる事が分つた ので，次の樣な寸法亡形狀のリングを作つて実驗 㐫る事とした。

\section{2. 實驗}
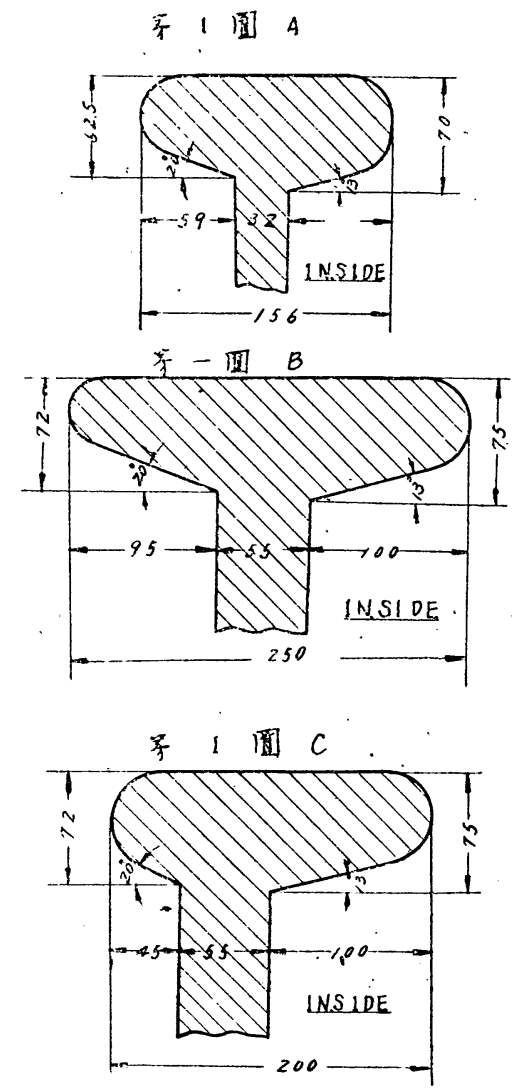

第 1 図A は現在使用中のもので第 1 図B．Cは 新しく作つをものである。特にCはフランヂの外 側がトラベラーの滑走に影響するとてろ少いので トラベラーを炭达み易认樣壮寸法を短くしたもの である。てれらを試用して比較する，亡次の結果に なつた。

’実驗に対する條件は

製品名 麻スフ混紡系 8's（麻65\%スフ35\%） リング径 $2 \frac{1}{4}$ in

スピンドル回轉数 2964r.p.m.

使用トラベラー L G 12

なお $\mathrm{A}$ リングは使用開始後 6 ケ月， B 及びCリ ングは使用初めである。トラベラー消粍関して は実測の結果は第1表のようになつた。

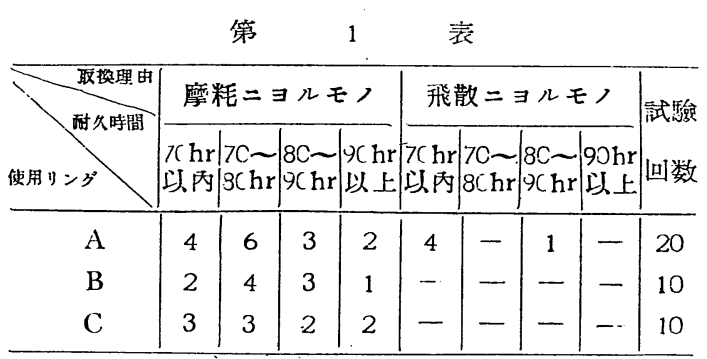

註 紊中の飛散はトラベラーが摩粍して飛散した数を 表し、摩粚によるるのはトラベラーとリング間の 臂粍が進行して摩摖抵抗が多くなつて糸町れが頻 慗となつた时に取りはづした数である。

本均耐久時間

今飛散したものをその時の耐久時間とし $70 \mathrm{hr}$ 以下を $70 \mathrm{hr}, 90 \mathrm{hr}$ 以上を $90 \mathrm{hr}$ ，その他は中間の 時間亡して平均值を求める之，

$$
\begin{aligned}
A & =\frac{70 \times 4+75 \times 6+85 \times 4+90 \times 2}{20} \\
& =76.5(\mathrm{hr}) \cdots \cdots \cdots \cdots \cdots \cdots(1) \\
B & =\frac{170 \times 2+75 \times 4+85 \times 3+90}{10} \\
& =78.5(\mathrm{hr}) \cdots \cdots \cdots \cdots \cdots \cdots(2)
\end{aligned}
$$




$$
\begin{aligned}
\mathrm{C} & =\frac{70 \times 3+75 \times 3+85 \times 2+90 \times 2}{10} \\
& =78.5(\mathrm{hr}) \cdots \cdots \cdots \cdots \cdots \cdots(3)
\end{aligned}
$$

以上は初めに期待した程の差違は得られなかつ

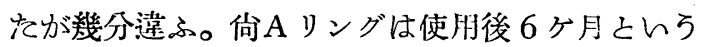
这々條件てあるので B.C リングも使用馴れすれ ば更に良数が表れるのを期街するととが出來 3。

今てれらの運動姿勢を画けば第 2 図の如くなる 第 2 図
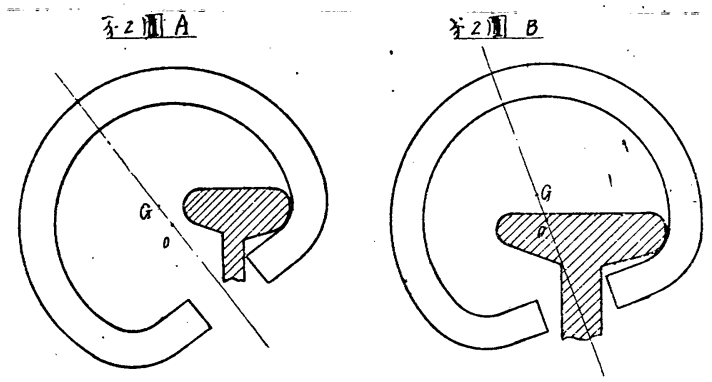

点Gは重心の位置を示す。トラベラーに作蒯する

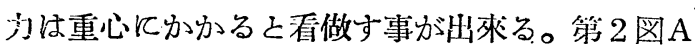
は第1図Aのリング亡トラベラーの関係を表し, 第 2 図Bは第 1 図 B.Cのリング亡トラベラーの 関係を表したものである。

此の図の狀態における遠心力を比較して見ると 的市

$$
\begin{aligned}
& \mathrm{W}=\text { トラベラーの重量 } \\
& \mathrm{n}=\text { トラベラーの回轉数 } \\
& \mathrm{r}=\text { リングの中心から重心迄の距離 } \\
& \mathrm{C}_{\mathrm{L}}=(\mathrm{W} / \mathrm{g}) \cdot(2 \pi \mathrm{n} / 60)^{2} \cdot \mathrm{r}
\end{aligned}
$$

第 2 図の A . B を比較すれば A の場合はトラベ

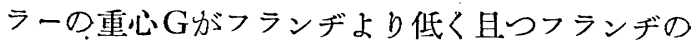
外側飞あるから，スピンドルの中心よりの距離は B比較して長く両方の垟は，

Aの場合のスピンドルの中心からトラベラーの 重心迄の距離を $\mathrm{r}_{1}$ とし， $\mathrm{B}$ の場合を $\mathrm{r}_{2}$ とすれ ば

$$
\begin{aligned}
& r_{1}=2.85+0.48=3.33(\mathrm{~cm}) \\
& r_{2}=2.85+0.465=3.315(\mathrm{~cm})
\end{aligned}
$$

今ボビンの径を 2 in 亡すれば遠心力は $A$ の場 合

$$
\begin{aligned}
\mathrm{C}_{\succeq} & =(0.7776 / 980) \cdot(2 \times 2919 \pi / 60)^{2} \\
& \times 3.33 \fallingdotseq 242.86(\mathrm{gr}) \cdots \cdots \cdots \cdots \cdot(4)
\end{aligned}
$$

Bの場合は

$$
\begin{aligned}
\mathrm{C}_{\mathrm{L}} & :=(0.7776 / 980)^{\prime} \cdot(2 \times 2919 \pi / 60)^{2} \\
& \times 3.315 \div 241.76(\mathrm{gr})
\end{aligned}
$$

即ち $1.1 \mathrm{~g}_{\mathrm{r}}$ の差である。乙の場合 L G 型トラ ベラーは1番手の重量差がlgrain $(0.0648 \mathrm{gr})$ で あるから 2 番手弱の苃を生じるととになる。トラ ベラーの耐久時間の差が式 (1) 及び (2)（3） 凡見る如く遠心力の計算 (4) 一（5）の差即ち $1 . \operatorname{lgr}$ 强んここからAの耐久時間が少くなつて居 る亡考えられる。

\section{3. 重心の計算}

此の計算の䉆とトラベラーの重心を求める方法 を述べる。

トラベラーの形狀を近似的に第 3 図の斜線の如 く考える。

1） Oを中心亡し O P を卅径亡する同

2) Oを中心亡しODを牛径よする円の F F' よ り上部の久円 (马形)

3） $\mathrm{O}$ を中ょし $\mathrm{OF}$ を半径とする円の $\mathrm{F} \mathrm{F}^{\prime}$ よ り.下部の久円

4) $\mathrm{F} \mathrm{F}^{\prime} \mathrm{iH}$ 近似的飞梯形亡洘え，梯形 $\mathrm{F} \mathrm{F}^{\prime} \mathrm{iH}$

5) 矩形 $K K^{\prime} L L^{\prime}$

とすれば（註單位miles=1/1000in）

1) 面積 $\mathrm{a}_{1}=\pi \times 227.5^{2}=162500$ 重心 $\mathrm{G}_{1}$ の $\mathrm{Y}$ 座標 $\mathrm{PG}_{1}=227.5$

2) 面積 $\mathrm{a}_{2}=\frac{\angle \mathrm{DOE}}{360} \times \pi \times 177.5^{2}+\mathrm{DC}$ $\times \mathrm{OC}=85380$

$$
(\mathrm{OC}=106.5)
$$

$\mathrm{OG}_{2}=\frac{(2 \mathrm{DC})^{3}}{12 \times \mathrm{a}_{2}}=21.8 \cdots$ (弓形の公式)

重心 $\mathrm{G}_{2}$ のY座標 $\mathrm{PG}_{2}=249.3$

3 ) 偭秒 $\mathrm{a}_{3}=\frac{(227.5)^{2}}{2(\theta-\sin \theta)}=34000$ (弓形の公式)

$$
\mathrm{OG}_{3}=\frac{\left(\mathrm{F} \mathrm{F}^{\prime}\right)^{2}}{12 \times \mathrm{a}_{3}}=157
$$

重心 $\mathrm{G}_{3}$ のY座標 $\mathrm{PG}_{3}=70.5$

4) $\mathrm{CG}_{4}=\frac{\mathrm{C} \mathrm{J}}{3} \times \frac{\mathrm{FF}^{\prime}+2 \mathrm{Hi}}{\mathrm{FF}^{\prime}+\mathrm{Hi}^{2}}=24.2$

$$
\text { (梯形の公式) }
$$

重心 $\mathrm{G}_{4}$ のY座標 $P_{4}=95.6$

面積 $\mathrm{a}_{4}=\frac{\mathrm{F} \mathrm{F}+\mathrm{Hi}}{2} \times \mathrm{C} \mathrm{J}=18222$

$$
\text { ( } \mathrm{C} \mathrm{J}=50 \text { ) }
$$

5) 面積 $\mathrm{a}_{5}=\mathrm{KK}^{\prime} \times \mathrm{KL}=5000$

$$
\text { (K L }=100)
$$




$$
\mathrm{CG}_{5}=25
$$

$\mathrm{G}_{5}$ のY座標 $\mathrm{PG}_{5}=94.8$

以上を次表任集めるょ

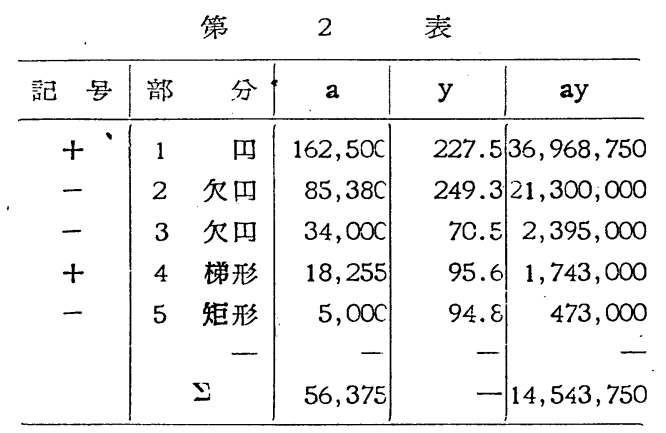

式に依つて

$\mathrm{Y}=\Sigma$ ay $/ \mathrm{A}=14543750 / 56375 \doteqdot 262.8$

即ち $\mathrm{PG}=262.8$

$$
\therefore \mathrm{OG}=35.3
$$

\section{4. 糸の撚數及び强度}

トラベラーの遠心力に依つて系がデリバリーを 離れた時既に何程の撚数があつて糸の强力がなけ れば糸切れの原因亡なるのを考えて，次に撚数亡 强度の試驗をして遠心力と比較した。第 3 表は捻 回試驗機に依つて作り試料10回の平均を求めた。

\section{（第 3 表）}

次に撚数亡强度との関係を調へるる爲長さ $\sin$ の 糸の热りを戻して之に重鏵をかけ糸の切れる時の 重力を測定した。（第 4 表）

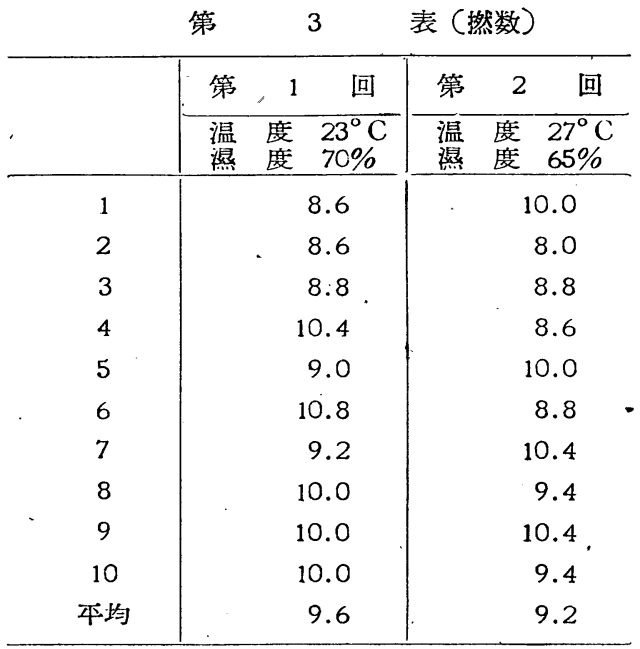

註 第5図は第 4 表を曲線で表したものである 第 3 表に見る如く試料怕撚数が 9.4 平均亡な るが第 4 表に依る亡撚戻し 8 回に於て强力が一番 ないが之を 1 と考えると撚戻し 4 回が 307gr で，

\begin{tabular}{|c|c|c|c|c|}
\hline $\begin{array}{l}\operatorname{lin} \text { 当 } \\
y \text { の撚 } \\
\text { 戾回数 }\end{array}$ & 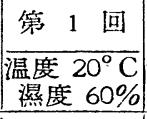 & $\left|\begin{array}{cc}\text { 第 } 2 \text { 回 } \\
\text { 温度 } & 22^{\circ} \mathrm{C} \\
\text { 潪度 } & 65 \%\end{array}\right|$ & $\begin{array}{|ccc|}\text { 第 } 3 & \text { 回 } \\
\text { 温度 } & 17^{\circ} \mathrm{C} \\
\text { 笽度 } & 85 \% \\
\end{array}$ & 平坞値 \\
\hline-3 & - & 1,300 & 1,075 & 1.187 .5 \\
\hline-2 & - & 1,300 & 1,150 & 1,225 \\
\hline-1 & - & 1,150 & 1,000 & 1,075 \\
\hline 0 & - & 850 & 1,070 & 960 \\
\hline 1 & $1, \infty 00$ & 850 & 1,050 & 966 \\
\hline 2 & 850 & 750 & 867 & 822 \\
\hline 3 & 400 & 550 & 633 & 527 \\
\hline 4 & 300 & 150 & 470 & 307 \\
\hline 5 & 150 & 150 & 111 & 137 \\
\hline 6 & 16 & 33 & 64 & 37.6 \\
\hline 7 & 20.6 & 19 & 21 & 20.2 \\
\hline 7.5 & - & 17 & -15 & 16 \\
\hline 8 & 17.0 & 16 & 14 & 15.6 \\
\hline 8.5 & - & 17.3 & 19 & 18. I5 \\
\hline 9 & 20 & 20 & 25.3 & 21.7 \\
\hline 10 & 11 & $3 o ́$ & 105 & 50.6 \\
\hline
\end{tabular}

第 4 衣 强力(gr)
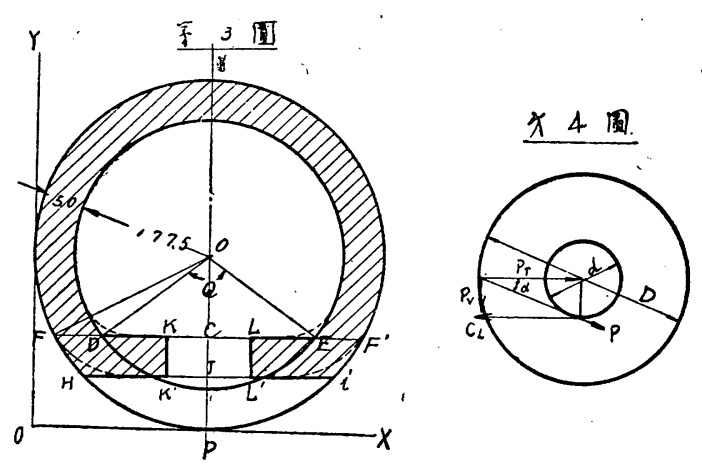

5 回が $137 \mathrm{gr}$ であるから，遠心力 $242 \mathrm{gr}$ 亿耐え る爲にはデリバリーを離れるとすぐ 4 〜 回の撚 数が禾から傳つて撚られて居なければ糸が切れ易 ん亡云ふ事が都えられる。勿論トラベラーは動力

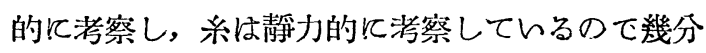
の相異は生するる今後の実驗を進める䉆の順序か 之考えて記錄する。

以上の事柄を次の式化当嵌めて計算する之次の 椂炕つた。

\section{5. 計 算}

a トラベラーの速度差による各種の作用 スピンドルの回轉数 : $2964 \mathrm{r} . \mathrm{p} . \mathrm{m}$.

每分潜出速度：284in/min

撩さつつあるボビン惩 : d in

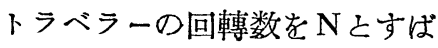

$$
\mathrm{N}_{1}=2964-\frac{284}{2 \pi}-=2919 \mathrm{r} \cdot \mathrm{p} \cdot \mathrm{m} \text {. }
$$


ボビン肯 2 in の時、

$$
\begin{gathered}
\mathrm{N}_{2}=2964-\frac{284}{\pi \% / 8}=2861 \mathrm{r} \cdot \mathrm{p} \cdot \mathrm{m} . \\
\text { ボビン径 } 7 / 8 \text { in の時 }
\end{gathered}
$$

撚数

$$
\begin{aligned}
& \mathrm{T}_{1}=\frac{2919}{284}=10.3 \\
& \mathrm{~T}_{2}=\frac{2861}{284}=10.1
\end{aligned}
$$

即ち然りの差はボビンの径の增大には殆んど開 題にならなん。然回試驗による撚数の平均は 9 ・ 4 回で撚縮みによる差亡思う。

\section{b 糸の張力}

トラペラーの遠心カを $\mathrm{C}_{\mathrm{L}}$ とすれば

$$
\begin{aligned}
& \mathrm{C}_{\mathrm{L}}=\frac{\mathrm{W}}{\mathrm{g}}(2 \pi \mathrm{n} / 60)^{2} \mathrm{r} \\
& \mathrm{r}=\text { リングの径….....21/4 } \mathrm{in}=2.85 \mathrm{~cm} \\
& \mathrm{~W}=\text { トラベラーの重量…..... } \\
& \mathrm{LG} 12=0.7776 \mathrm{gr}(12 \mathrm{grain}) \\
& \mathrm{C}_{\mathrm{L} 1}=\frac{0.7776}{980}\left(\frac{2 \times 2919 \pi}{60}\right)^{2} \times 2.85 \\
& \quad \fallingdotseq 210 \mathrm{gr} . \\
& \mathrm{C}_{\mathrm{L} Z}=\frac{0.7776}{980}\left(\frac{2 \times 2861 \pi}{60}\right)^{2} \times 2.85 \\
& \quad=203 \mathrm{gr}
\end{aligned}
$$

第4 図はトラベラーよりボビンに糸が捲かれる 狀態を示す。

$$
\begin{aligned}
& \mathrm{D}=\text { リングの径 } \\
& \mathrm{d}=\text { 捲きつつあるボビン径 } \\
& \mathrm{P}=\text { トラベラーより末管に捲かれる張力, } \\
& \mathrm{P} \text { は } \mathrm{P}_{\mathrm{r}} \mathrm{P}_{\mathrm{v}} \text { の } 2 \text { 力に分けられる, }
\end{aligned}
$$

略算的に余り問題にならなん力を省略すれば

$\left(\mathrm{C}_{\mathrm{L}}-\mathrm{P} \cos a\right)^{2}+\mathrm{P}^{2} / 4=\mathrm{d}(\mathrm{dp} / \mathrm{D} \mu)^{2} \ldots \ldots \ldots$

摩擦係数 $\mu=0.045$ 亡すれば

$\mathrm{d}=2$ in の時は

$$
\begin{aligned}
& \cos a=\sqrt{\mathrm{D}^{2}-\mathrm{d}^{2}} / \mathrm{D}=0.465 \\
& (210-0.465 \mathrm{P})^{2}+\mathrm{P}^{2} / 4=(0.89 \mathrm{P} / 0.45)^{2}
\end{aligned}
$$

$3.443 \mathrm{P}^{2}+195.3 \mathrm{P}-44100=0$

$$
\therefore \mathrm{P}_{1} \doteqdot 116.5 \mathrm{gr}
$$

$\mathrm{d}=7 / 8$ in の時は同樣に

$\therefore \mathrm{P}_{2} \doteqdot 123 \mathrm{gr}$

フロントローラーとデリバリー間の系の張力を
X亡すれば，

$X=0.9 \times \frac{p}{f}$

$\mathrm{f}$ 二 糸之トラベラーの滑り摩擦係数

$\mathrm{f}=2.5-0.8 \sin a+0.2 \frac{\mathrm{h}}{\mathrm{l}}$

$\mathrm{h}=$ リングレール最低よりの高さ

$l=$ リングレール移動最大距離

$\mathrm{Q}=$ トラベラーに入る糸の張力

$\mathrm{Q}=\mathrm{P} / \mathbf{f}$

デリバリーよりトラベラー迄の糸の張力は殆ん ぞQ反等しh,

$\mathrm{Q}=\mathrm{P} / \mathrm{f}$ の時

（イ）リッグレール最低の場合

$\mathrm{f}=2.5-0.2 \sin a+0.2$

$\sin \alpha=2 / 2.25=0.465$

$X=0.9 \times \frac{116.5}{2.5-0.8 \times 0.465+0.2}$ $=44.0 \mathrm{gr}$

$\mathrm{Q}=\mathrm{P} / \mathrm{f} \doteqdot 50 \mathrm{gr}$

(口) リングレール最高の場合

$\mathrm{f}=2.5-0.8 \sin a$

$\hat{X}=0.9 \times \frac{116.5}{2.5-0.8 \times 0.465}=48.8 \mathrm{gr}$

$\mathrm{Q}=\mathrm{P} / \mathrm{f} \doteqdot 55 \mathrm{gr}$

$\mathrm{d}=\tau / 8$ in の時

（イ）リングレール最低の場合

$$
X=0.9 \times \frac{123}{2.5-0.8 \times 0.384+0.2} \div 51.4 \mathrm{gr}
$$

(ロ )ングレール最高の場合

$$
\begin{aligned}
& X=0.9 \times \frac{1.23}{2.5-0.8 \times 0.384}=49.9 \mathrm{gr} \\
& \mathrm{Q}=\mathrm{P} / \mathrm{f}=56.6 \mathrm{~g} \mathrm{r}
\end{aligned}
$$

即ち上記の條件に於ては

フロントローラーとデリバリー間の糸の張力 $44 \sim 50 \mathrm{gr}$

トラベラーより木管に捲かれる系の張力は $116 \sim 123 \mathrm{gr}$

トラベラーに入る糸の張力は 50〜 57gr である。

上記の計算によつてもデリバリーよトラベラー 間の糸の張力は 44〜50gr でトラベラーの姿勢か ら遠心力の分力が此の張力に釣合う事が考えられ る。赛際にはトラベラーにかかる各種の力は複雜 


\section{でこの釣合も亦複雜である。}

此の遠心力の分力はトラベラーの水平姿勢より 活動姿勢になる角度によつてわかる。図Aの場合 はA GB 傾斜して居り, 図B 注 CGD傾科して居 るから，図Aは $\overline{\mathrm{AB}}$ ガ，図 $\mathrm{B} て ゙ は \overline{C D}$ が垂直に㗢 く分力亡をる。前記の遠心力から分力を求めると $\angle \mathrm{A} \mathrm{GB}=38^{\circ}$

$\angle \mathrm{CGD}=20^{\circ}$

$\therefore \quad \mathrm{A} \mathrm{B}=\mathrm{GA} \times \tan 38^{\circ} \fallingdotseq 190 \mathrm{gr}$

$\mathrm{CD}=\mathrm{GC} \times \tan 20^{\circ} \fallingdotseq 8 \lg \mathrm{r}$

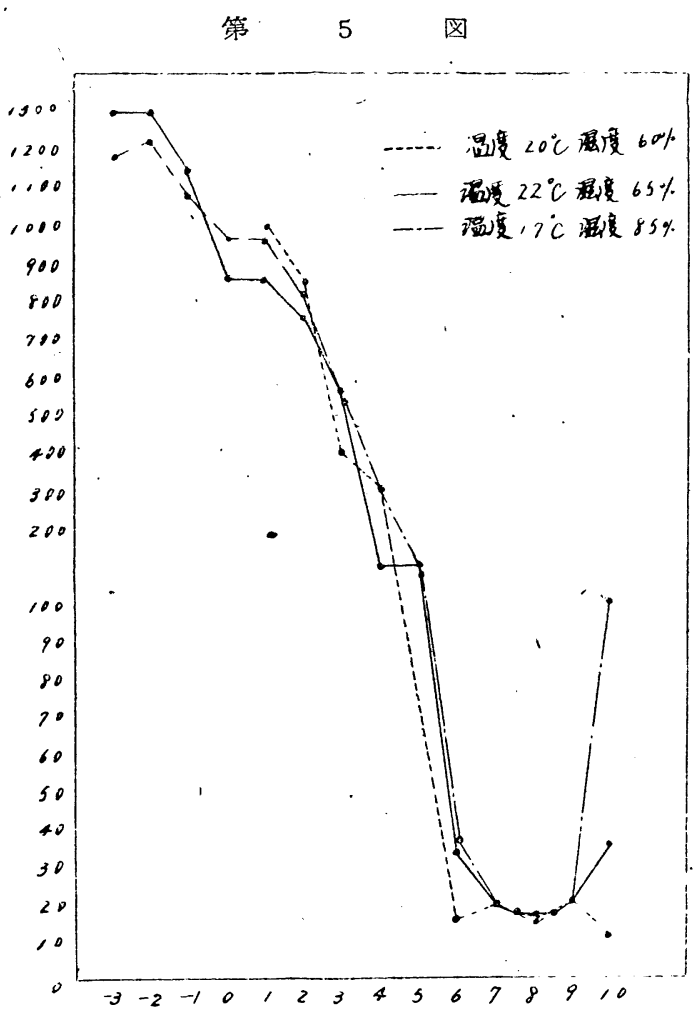

、記の計算之第 5 図に見られる如く図Aは糸の 張力よりトラペラーの傾科しよゔとする重力の方 が大きんからトラペラーの足がリングの外側面に 衝突して衝擊が起つて振動となる事が侤えられ る。

\section{6. 結論}

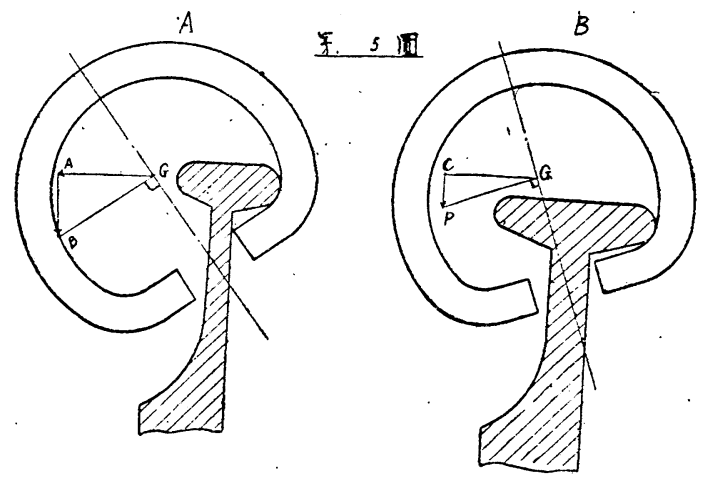

上記の計算によつても，トラベラーに入る系の

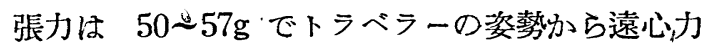
とトラベラーより木管に捲かれる系の tensionの 中心方向の分力之の差の垂直方向の分力が此の張 力飞釣合ふ事が侤えられる。

実際にはトラベラーにかかる各種の力は複雜で 此の釣合も又複雜である。

略算的にトラベラーより木管に捲かれる禾の tensionを $120 \mathrm{~g}$ とするならば

中心方向の分力 $\mathrm{Pr}=\mathrm{P} \cos a$

$$
\mathrm{d}=2^{\prime \prime} \text { の時 }
$$

$$
\cos a=0.465
$$

$\therefore \operatorname{Pr}=120 \times 0.465=55.8 \mathrm{~g}$

$\therefore \quad A G=242.86-55.8 \fallingdotseq 187$

$\therefore \mathrm{GC}=241.76-55.8 \div 186$

$\angle \mathrm{AGB}=38^{\circ} \angle \mathrm{CGD}=20^{\circ}$

$\therefore \mathrm{A} \mathrm{B}=\mathrm{AG} \times \tan 38^{\circ}=187 \times 0.7813 \fallingdotseq 146 \mathrm{~g}$ $\mathrm{CD}=\mathrm{CG} \times \tan 20^{\circ}=186 \times 0.364 \fallingdotseq 67.5 \mathrm{~g}$

以上の計算に見られる如く, 各種の力の釣合に よつてトラベラーが図Aの如き姿勢で回轉してん る事は図B 亿較べて惡い事がわかる。即ちAの場 合は B 亿較べてトラベラー足がリングの外側面に 衝突して，衝擊を起し振動となり，系切の機會を 多くし，トラベラーの摩粍を早めると洘えられ る。トラベラーの滑走姿勢が正しh狀態に保つ事 は大切であり，その事は害際にも見壮された。此 の振動の影響に就ては現在研究中であるので一應 中間報告として発表した。 